\title{
Regeneração de um trecho de floresta de restinga na Reserva Ecológica Estadual de Jacarepiá, Saquarema, Estado do Rio de Janeiro: II - Estrato arbustivo*
}

\author{
Cyl Farney Catarino de Sá ${ }^{1}$
}

\begin{abstract}
RESUMO
O estrato arbustivo representa o estágio mais adiantado da regeneração da floresta de restinga da Reserva Ecológica Estadual de Jacarepiá, impactada em 25\% da área total em 1986. As espécies Trema micrantha e Aegiphila sellowiana são as pioneiras mais abundantes. O método de parcelas, embora moroso, foi eficiente, pois permite o acompanhamento da regeneração. As trepadeiras, no momento não estão relacionadas à reversão da regeneração. Espécies arbóreas que ocorrem na floresta não perturbada parecem ser favorecidas com perturbação; outras são desfavorecidas e outras são capazes de rebrotar. De 110 táxons encontrados, somente 21 são comuns a outros estudos realizados no Brasil em áreas perturbadas de restinga e mata atlântica.
\end{abstract}

Palavras-chave: regeneração natural, corte raso, rebrota, florística, estrutura

\begin{abstract}
Shrub strata represents the most advantaged regeneration stage of restinga forest in the Jacarepia State Ecological Reserve, Rio de Janeiro, which is $25 \%$ impacted of the total forest area in 1986 . The pioneers Trema micrantha and Aegiphila sellowiana are the most abundant. Although slow the quadrat method was efficient and allowed monitoring forest regeneration. At present, lianas are not interfering in the regeneration process. The tree species in the primary forest seem to gain with forest disturbance, some are not affected and others are able to re-grow. Within 110 species found in the study area only twenty-one were recorded in similar studies of Brazilian disturbed areas.
\end{abstract}

Keywords: Sandy Coastal Plain, Regeneration, logging, regrowth, forest structure

\section{INTRODUÇÃO}

Recentemente o estudo e a recuperação de áreas florestais perturbadas nos trópicos, vem tomando cada vez mais espaço no cenário científico, movidos também pelos problemas causados pelo intenso crescimento populacional. Um deles, a destruição das florestas das margens de rios e reservatórios, protegidas por lei, tem colocado em risco o abastecimento de água para consumo humano em muitas cidades. Subsídios para a proteção, conservação e recuperação de matas ciliares podem ser encontrados respectivamente em Silva Jr. (2001), que analisou a efetividade do Código Florestal na proteção destas matas, e na obra multidisciplinar de Rodrigues \& Leitão
Filho (2000), abordando desde modelos de recuperação a organismos indicadores de proteção.

Os princípios da recuperação florestal têm sido fundamentados nos trabalhos de Richards (1952) e Budowski (1965), onde respectivamente as idéias sobre dinâmica proporcionada pela abertura de clareiras e o caráter sucessional das espécies são peças chaves neste processo. A sequiência florística e estrutural em grandes áreas perturbadas é determinada principalmente pelo tamanho da clareira formada, presença de propágulos no local e a distância a fontes de sementes (Hartshorn 1978; Bazzaz \& Picket 1980). No Brasil, estudos relacionados a perturbações vem sendo desenvolvidos em diversos ecossistemas, abor-

\footnotetext{
* Parte da Dissertação de Mestrado, defendida pelo autor em dezembro de 1993 na Universidade Federal do Rio de Janeiro. Bolsa CNPq No. 830192/91-3.

${ }^{1}$ Pesquisador Jardim Botânico do Rio de Janeiro - Programa Zona Costeira, Rua Pacheco Leão 915 - Rio de Janeiro/RJ Brasil Cep:22.460.030 E-mail: cfarney@jbrj.gov.br
} 
dando diversos aspectos da regeneração natural e sucessão secundária (Custódio Filho et al.. 1994, Silva $\mathrm{F}^{\circ}$ et al. 1995, Durigan et al. 1997, Sampaio et al. 1998, Gonçalves \& Sá 1998, Mariano et al. 1998, Tabarelli \& Mantovani 1999a, Dorneles \& Negrelle 2000), clareiras (Almeida 1990, Tabarelli \& Mantovani 1997, Araujo et al. 1997, Tabarelli \& Mantovani 1999b, Martins \& Rodrigues 1999), fragmentação (Tabanez et al. 1997, Lawrence et al. 1998, Bernacciet al. 1998, Nascimento et al. 1999).

A velocidade de destruição dos ecossistemas costeiros brasileiros, associada à intensa demanda turística, vem superando, até o momento, os esforços dos cientistas empenhados no conhecimento da sua diversidade, funcionamento e capacidade de recuperação. Os antecedentes dessas ações no litoral estão relacionados à diminuição do impacto dos problemas ocasionados pela movimentação de areias em dunas ativas (Matos 1947, Barbosa 1948, Juvêncio 1959). Mas somente a partir da década de 70 surgiram estudos abordando aspectos da regeneração natural da vegetação (Araújo \& Peixoto 1977; Sá 1993, 1996; Oliveira Filho \& Carvalho 1993; Moura 1995; Cirne \& Scarano 1996; Araujo et al. 1997; Miranda et al. 1997, Gonçalves \& Sá 1998,) e sobre espécies focais (Zaluar \& Scarano 2000) em diferentes comunidades de restinga e áreas geográficas. Estudos de propagação de espécies para a recuperação de áreas fora dos sistemas de dunas são mais recentes ainda (Silva \& Zamith 1994, Zamith \& Dalmaso 2000, Carrasco \& Castanheira 2000). Independente da formação vegetal, amazônica ou atlântica s.l., os troncos múltiplos originários de fontes de rebrotas (caules, raízes) exercem papel fundamental e diferenciador na seqüência da regeneração da vegetação, quando comparado a áreas onde estas fontes foram retiradas (Uhl et al. 1988; Araújo et al. 1997; Gonçalves \& Sá 1998, Oliveira 1999; Assumpção e Nascimento 2000). Troncos múltiplos inclusive podem estar associados também à não intervenção humana, podendo ser uma característica da própria floresta, como encontrado por Dunphy et al. (2000) em floresta subtropical semidecídua em Porto Rico. As restingas associadas a sua diversificação de comunidades e características abióticas apresentam severas condições ao restabelecimento da vegetação após perturbações e têm sido pouco estudadas sob este aspecto. Assim, este trabalho tem por objetivo fornecer informações sobre a florística e estrutura de um trecho de floresta de restinga sob regeneração natural seis anos após corte raso com destocamento.

\section{MATERIAL E MÉTODOS}

\section{Área de Estudo}

A Reserva Ecológica Estadual de Jacarepiá (REEJ) com 1.250 ha. está localizada (Fig. 1) no Município de Saquarema/RJ (22\%47'$\left.22^{\circ} 57^{\prime} \mathrm{S} / 42^{\circ} 20^{\prime}-42^{\circ} 43^{\prime} \mathrm{W}\right)$. Situa-se na região leste do Estado, denominada de "Baixadas Litorâneas" (Domingues et al. 1976) cujo relevo é plano e suavemente ondulado, e também inserida no "Centro de Diversidade Vegetal de Cabo Frio", um dos 14 centros de alta diversidade indicados para o Brasil (Araujo 1997). A precipitação média para o decênio 1982/1991, obtida de dados da Estação Saquarema/ SERLA (22 $\left.55^{\prime} 50^{\prime \prime} \mathrm{S} / 42^{\circ} 30^{\prime} 10^{\prime \prime} \mathrm{W}\right)$, foi de $987 \mathrm{~mm} / \mathrm{ano}$.

A floresta de restinga estendia-se continuamente por todo o cordão arenoso interno, apresentando apenas um trecho com significativa área perturbada, anterior à destruição em 1986. Informações de moradores locais indicam que a parte da floresta desmatada na década de 70 foi utilizada para plantio de abacaxi. Mencionam também que diversas espécies, de diferentes comunidades vegetais da restinga, são utilizadas com variados fins: medicinais, alimentícios, energéticos etc. (Fonseca 1998). A área tem sido estudada por botânicos do Jardim Botânico do Rio de Janeiro, FEEMA e da UFRJ desde o ano de 1986 (Sá 1992), e, passada mais de uma década da criação da Reserva, a mesma não dispõe de qualquer infraestrutura, muito menos a questão legal foi resolvida. Este quadro tem propiciado impactos por diferentes agentes com intensidades e magnitudes variadas (invasão de áreas, 


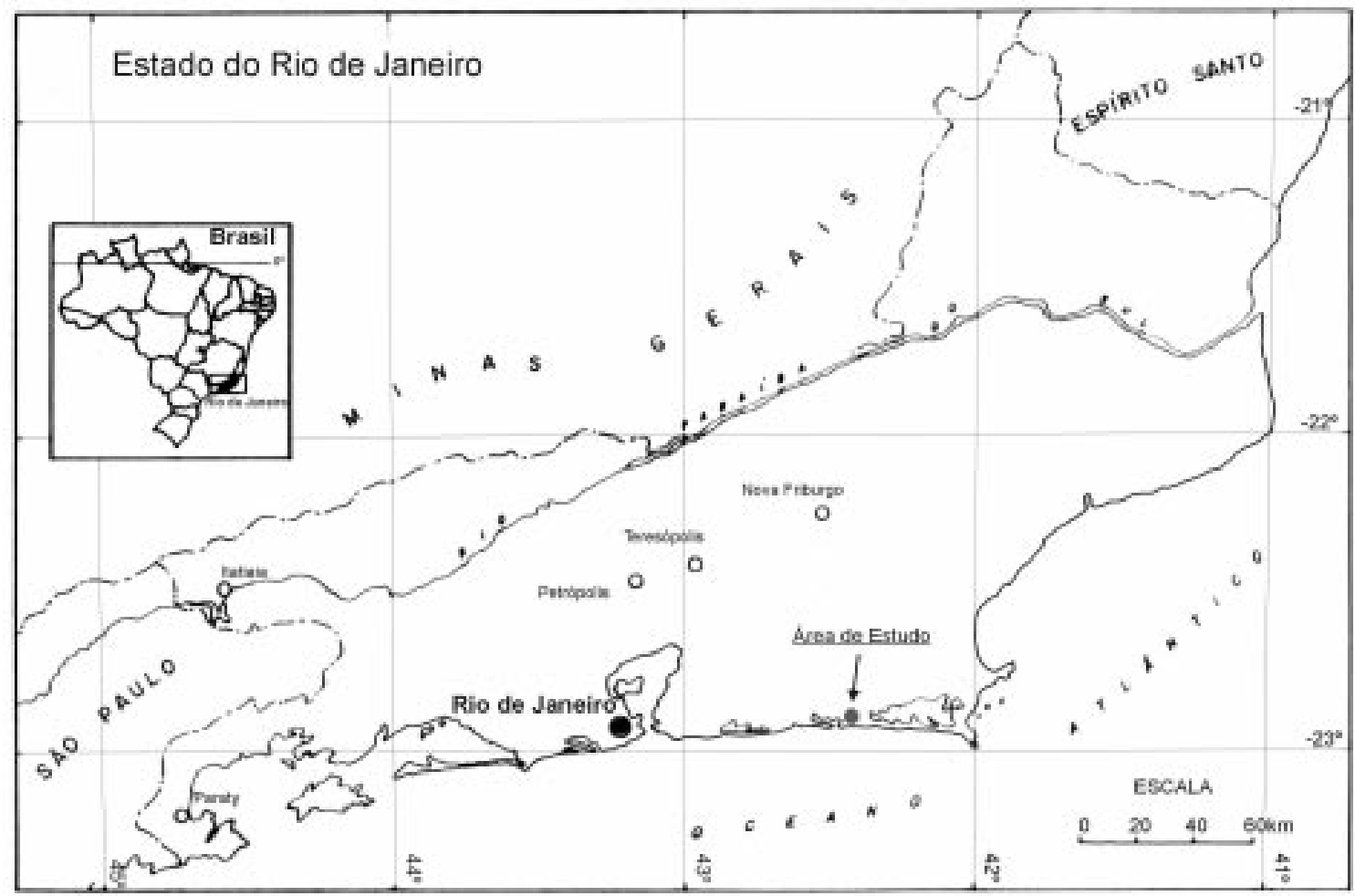

Figura 1 - Localização da área estudo.

extração madeireira ou de plantas ornamentais, caça, pastoreio, queimadas, abertura de vias, entre outras), o que tem acarretado um rápido empobrecimento da vegetação.

O local onde foi realizado o levantamento corresponde à Gleba No. 6 do Loteamento Vilatur Saquarema, totalizando 18,5 ha em formato quadrado, embargado pela FEEMA em 1986. A área foi segmentada por tratores de esteira (corte raso com destocamento) em 17 arruamentos que medem $20 \times 200 \mathrm{~m}$, totalizando cerca de 7,2 ha de área perturbada ou cerca de $40 \%$ da referida Gleba. As áreas perturbadas por tratores, até o momento, não vêm sofrendo ações antrópicas que influenciem na continuidade da regeneração.

\section{Metodologia}

Neste estudo foi adotado o conceito de Gomez-Pompa \& Burley (1991) de regeneração pela sua abrangência ao incluir sucessão secundária natural e tipos de manipulação florestal intencionais. Para a amostragem da vegetação perturbada seis anos após o impacto de tratores para abertura de arruamentos, utilizou-se o método de parcelas. Nos 15 arruamentos foram delimitadas 80 parcelas fixas de $5 \mathrm{~m}$ x $5 \mathrm{~m}$ (0,2 ha) distanciadas entre si $40 \mathrm{~m}$. Em cada um dos 14 arruamentos de $200 \mathrm{~m}$ x $20 \mathrm{~m}$ foram marcadas 5 parcelas e, no maior deles (400 m x $20 \mathrm{~m}$ ), foram marcadas 10 parcelas.

Todos os indivíduos com DAS $\geq 2,5 \mathrm{~cm}$ foram marcados, numerados e medidos e posteriormente coletados e herborizados para identificação. Não foi estabelecido limite mínimo para altura e indivíduos mortos não foram considerados. Em planilha de campo foram anotados dados referentes ao número do arruamento e da parcela, família, espécie, altura, DAS, estado reprodutivo e hábito. Os trabalhos de campo foram desenvolvidos no período de agosto a novembro de 1992 (seis anos após o impacto). O material foi identificado, com auxílio de especialistas para alguns grupos taxonômicos, e encontra-se depositado no Herbário do Jardim Botânico do Rio de Janeiro (RB).

Os cálculos dos parâmetros fitossociológicos seguiram Brower \& Zar (1977). 


\section{RESULTADOS \& DISCUSSÃO}

\section{Fisionomia e florística}

Seis anos após o distúrbio, as áreas perturbadas da Reserva Ecológica Estadual de Jacarepiá (REEJ) apresentam aspecto emaranhado composto por trepadeiras, arbustos e árvores, com raros indivíduos atingindo entre 5 e $7 \mathrm{~m}$ de altura. $\mathrm{O}$ estrato arbustivo representa um estágio mais adiantado da regeneração da floresta de res-tinga nas clareiras formadas, em relação ao estrato herbáceo definido por Sá (1993, 1996) para esta área. Com base na lista de espécies apresentada na Tabela 1, predominaram: árvores (39\%), arbustos (33\%), trepadeiras (23\%) e sub-arbustos (5\%). Ocorreu um considerável decréscimo na riqueza de trepadeiras (41\%) do estrato herbáceo (Sá 1996) para o estrato arbustivo (23\%), cuja variação aparentou ser afetada pelo método utilizado.

Além de serem evidentes na paisagem perturbada, as trepadeiras desempenham um importante papel nos dois estratos, principalmente por crescerem isoladamente formando moitas. Nos locais onde os tratores alteraram mais profundamente o perfil do solo, poucas espécies conseguem se instalar, entretanto as trepadeiras, principalmente da família Bignoniaceae que tem alta capacidade de rebrota (Gentry 1977), cobrem o substrato com extensas ramificações junto ao solo, na falta de hospedeiros. Por outro lado, árvores (16\% para $39 \%$ ) e arbustos (23\% para $33 \%$ ) aumentaram significativamente de importância em relação ao estrato herbáceo (Sá 1993, 1996), destacando-se as pioneiras arbóreas Trema micrantha e Aegiphila sellowiana, a primeira, considerada uma pioneira largamente en-

Tabela 1 - Lista das espécies encontradas nas parcelas da formação arbustiva da área peturbarda por tratores na Reserva Ecológica Estadual de Jacarepiá. Legenda: * encontradas na formação herbácea Sá (1996). Col. º = Coletor e número da coleta, $\mathrm{CF}=\mathrm{C}$.Farney, $\mathrm{HB}=$ Hábito (Arv=árvore, $\mathrm{Arb}=$ arbusto, Tre=trepadeira)

\begin{tabular}{|c|c|c|c|}
\hline FAMÍLIA & ESPÉCIE & Col. $\mathbf{N}^{\circ}$ & HB \\
\hline \multirow[t]{2}{*}{ 1. Anacardiaceae } & Astronium graveolens Jacq. * & CF 3722 & Arv \\
\hline & Schinus terebinthifolius Raddi $*$ & CF 3723 & Arb \\
\hline 2. Annonaceae & Annona acutiflora Mart. & CF 3724 & Arv \\
\hline \multirow[t]{3}{*}{ 3. Apocynaceae } & Anartia oblongifolia (A.DC.) Markgr. & CF 3725 & Arb \\
\hline & Aspidosperma parvifolium A.DC. & CF 3726 & Arv \\
\hline & Tabernaemontana laeta Mart. * & CF 3727 & Arv \\
\hline \multirow[t]{4}{*}{ 4. Bignoniaceae } & Adenocalymma trifoliatum (Vell.) R.C.Laroche * & CF 3728 & Tre \\
\hline & Amphilophium vauthieri A.DC. * & CF 3729 & Tre \\
\hline & Arrabidaea conjugata (Vell.) Mart. * & CF 3730 & Tre \\
\hline & Macfadyena sp * & CF 3731 & Tre \\
\hline 5. Bombacaceae & Bombacopsis stenopetala (Casar.) A.Robyns & CF 3732 & Arv \\
\hline \multirow[t]{3}{*}{ 6. Boraginaceae } & Cordia verbenacea DC. * & CF 3733 & Arb \\
\hline & Cordia superba Cham. & CF 3734 & Arv \\
\hline & Tournefortia membranacea (Gardner) DC. * & CF 3735 & Tre \\
\hline \multirow[t]{3}{*}{ 7. Cactaceae } & Opuntia brasiliensis (Willd.) Haw. & CF 3736 & Arv \\
\hline & Pereskia aculeata Mill. * & CF 3737 & Tre \\
\hline & Pilosocereus arrabidae (Lem.) Byles \& G.D.Rowley & $\mathrm{CF} \mathrm{s} / \mathrm{n}$ & Arb \\
\hline 8. Capparaceae & Capparis flexuosa (L.) L. & CF 3738 & Tre \\
\hline \multirow[t]{4}{*}{ 9. Compositae } & Baccharis serrulata (Lam.) Pers. & $\mathrm{CF} s / \mathrm{n}$ & Sub \\
\hline & Eupatorium lundianum DC. * & CF 3739 & Tre \\
\hline & Eupatorium maximilianii Schrad. ex DC. * & CF 3722 & Sub \\
\hline & Indet.1 & $\mathrm{CF} s / \mathrm{n}$ & Sub \\
\hline 10. Connaraceae & Connarus nodosus Baker * & CF 3740 & Arb \\
\hline \multirow[t]{2}{*}{ 11. Euphorbiaceae } & Algernonia obovata (Mull. Arg.) Mull. Arg. & CF 3741 & Arv \\
\hline & Manihot aff tripartita (Spreng.) Mull Arg. * & $\mathrm{CF} s / \mathrm{n}$ & Arb \\
\hline
\end{tabular}


Regeneração de um trecho de floresta de restinga na Reserva Ecológica Estadual de Jacarepiá, Saquarema, Estado do Rio de Janeiro: II - Estrato arbustivo

\begin{tabular}{|c|c|c|c|}
\hline FAMÍLIA & ESPÉCIE & Col. $\mathbf{N}^{\circ}$ & HB \\
\hline \multirow[t]{2}{*}{ 12. Flacourtiaceae } & Casearia aff decandra Jacq. * & CF 3743 & Arv \\
\hline & Casearia oblongifolia Cambess. & CF 3742 & Tre \\
\hline \multirow[t]{2}{*}{ 13. Hippocrateaceae } & Salacia arborea (Leandro) Peyr. * & CF 3745 & Tre \\
\hline & Hippocratea volubilis L. * & CF 3744 & Tre \\
\hline 14. Icacinaceae & Leretia cordata Vell. & CF 3746 & Arb \\
\hline 15. Indet.1 & Indet. 1 & $\mathrm{CF} \mathrm{s} / \mathrm{n}$ & Arb \\
\hline 16. Indet. 2 & Indet. 2 & $\mathrm{CF} \mathrm{s} / \mathrm{n}$ & Arb \\
\hline 17. Indet. 3 & Indet. 3 & $\mathrm{CF} \mathrm{s} / \mathrm{n}$ & Arb \\
\hline 18. Indet.4 & Indet.4 & $\mathrm{CF} \mathrm{s} / \mathrm{n}$ & Arb \\
\hline 19. Indet.5 & Indet.5 & $\mathrm{CF} \mathrm{s} / \mathrm{n}$ & Arb \\
\hline \multirow[t]{2}{*}{ 20. Lauraceae } & Ocotea notata (Nees.) Mez & CF 3748 & Arb \\
\hline & Ocotea $\mathrm{sp}$ & CF 3747 & Arv \\
\hline 21. Leguminosae Caes. & Swartzia apetala Raddi $*$ & CF 3749 & Arv \\
\hline \multirow[t]{4}{*}{ 22. Leguminosae Mim. } & Albizia polycephala (Benth.) Killip ex Record & CF 3750 & Arv \\
\hline & Inga maritima Benth. * & CF 3751 & Arv \\
\hline & Mimosa ceratonia L. * & CF 3752 & Tre \\
\hline & Parapiptadenia pterosperma (Benth.) Brenan & CF 3753 & Arv \\
\hline \multirow[t]{5}{*}{ 23. Leguminosae Pap. } & Machaerium hirtum (Vell.) Stellfeld $*$ & CF 3755 & Arv \\
\hline & Machaerium lanceolatum (Vell.) J.F. Macbr. * & CF 3756 & Arv \\
\hline & Machaerium pedicellatum Vogel & $\mathrm{CF} 3757$ & Arv \\
\hline & Poecilanthe falcata (Vell.) Heringer* & CF 3754 & Arv \\
\hline & Pterocarpus rohrii Vahl & CF 3758 & Arv \\
\hline 24.Loganiaceae & Strychnos parvifolia DC. * & CF 3759 & Tre \\
\hline 25. Malpighiaceae & Byrsonima sericea DC. * & CF 3760 & Arv \\
\hline 26. Malvaceae & Abutilon esculentum A.St.-Hil. & CF 3761 & Arb \\
\hline 27. Menispermaceae & Chondodendrum platiphyllum (A.St.Hil.) Miers * & CF 3762 & Tre \\
\hline \multirow[t]{8}{*}{ 28. Moraceae } & Brosimum guianense (Aubl.) Huber * & CF 3764 & Arb \\
\hline & Cecropia $\mathrm{sp}$ & CF 3765 & Arv \\
\hline & Ficus citrifolia Mill. & CF 3766 & Arv \\
\hline & Ficus clusiifolia Schott. & CF 3767 & Arv \\
\hline & Ficus hirsuta Schott. & CF 3768 & Arv \\
\hline & Ficus spl & CF 3693 & Arv \\
\hline & Ficus sp2 & CF 3769 & Arv \\
\hline & Sorocea hilarii Gaudich. * & CF 3763 & Arb \\
\hline \multirow[t]{7}{*}{ 29. Myrtaceae } & Calyptranthes sp & CF 3771 & Arb \\
\hline & Eugenia repanda O.Berg & CF 3770 & Arb \\
\hline & Marlierea schottii Legrand & CF 3772 & Arv \\
\hline & Indet.1 & CF 3774 & Arb \\
\hline & Indet. 2 & CF 3775 & Arb \\
\hline & Indet. 3 & CF 3773 & Arb \\
\hline & Indet.4 & CF 3776 & Arb \\
\hline \multirow[t]{3}{*}{ 30. Nyctaginaceae } & Bougainvillea spectabilis Willd. * & CF 3777 & Tre \\
\hline & Guapira opposita (Vell.) Reitz & CF 3778 & Arv \\
\hline & Guapira sp * & CF 3779 & Arb \\
\hline 31. Ochnaceae & Ouratea cuspidata (A.St.-Hil.) Engl. & CF 3780 & Arb \\
\hline 32. Phytolaccaceae & Seguiera americana $\mathrm{L} . *$ & CF 3781 & Tre \\
\hline \multirow[t]{2}{*}{ 33. Polygonaceae } & Coccoloba arborescens (Vell.) How. * & CF 3782 & Tre \\
\hline & Ruprechtia lundii Meisn. & CF 3783 & Arv \\
\hline \multirow[t]{3}{*}{ 34. Rubiaceae } & Guettarda viburnoides Cham. \& Schltdl. * & CF 3784 & Arv \\
\hline & Psychotria aff. brachyceras Mull. Arg. & $\mathrm{CF} s / \mathrm{n}$ & Arb \\
\hline & Staelia thymoides Cham. \& Schltdl. * & CF 3702 & Erv \\
\hline
\end{tabular}

Rodriguésia 53 (82): 5-23. 2002 


\begin{tabular}{|c|c|c|c|}
\hline FAMÍLIA & ESPÉCIE & Col. $\mathbf{N}^{\circ}$ & HB \\
\hline 35. Rutaceae & Pilocarpus spicatus A.St.-Hil. & CF 3785 & Arb \\
\hline \multirow{4}{*}{ 36. Sapindaceae } & Allophyllus puberulus Radlk. & CF 3786 & Arb \\
\hline & Matayba guianensis Aubl. * & CF 3787 & Arv \\
\hline & Paullinia racemosa Wawra* & CF 3788 & Tre \\
\hline & Paullinia weinmanniaefolia Mart. * & CF 3789 & Tre \\
\hline \multirow[t]{4}{*}{ 37. Sapotaceae } & Chrysophyllum januariense Eichler & CF 3790 & Arv \\
\hline & Manilkara subsericea (Mart.) Dubard & CF 3791 & Arv \\
\hline & Pouteria grandiflora (A.DC.) Baehni & CF 3792 & Arv \\
\hline & Pouteria reticulata (Engl.) Eyma & CF 3793 & Arv \\
\hline 38. Simaroubaceae & Simaba cuneata A.St.-Hil \& Tul. & CF 3794 & Arv \\
\hline \multirow[t]{7}{*}{ 39. Solanaceae } & Aureliana fasciculata (Vell.) Sendtn. * & CF 3795 & Arb \\
\hline & Cestrum laevigatum Schltdl. * & CF 3796 & Arb \\
\hline & Solanum aturense Humb. \& Bonpl. ex Dunal * & CF 3797 & Arb \\
\hline & Solanum inaequale Vell. & CF 3798 & Arb \\
\hline & Solanum paniculatum $\mathrm{L} . *$ & CF 3799 & Arb \\
\hline & Solanum subscandens Vell. * & CF 3800 & Arb \\
\hline & Solanum sp * & CF 3801 & Arb \\
\hline 40. Theophrastaceae & Clavija spinosa (Vell.) Mez & CF 3802 & Sub \\
\hline 41. Trigoniaceae & Trigonia villosa Aubl. * & CF 3803 & Tre \\
\hline \multirow[t]{2}{*}{ 42. Ulmaceae } & Celtis sp * & CF 3718 & Arb \\
\hline & Trema micrantha (L.) Blume * & CF 3804 & Arv \\
\hline \multirow[t]{3}{*}{ 43. Verbenaceae } & Aegiphila sellowiana Cham.* & CF 3805 & Arb \\
\hline & Lantana aff. camara $\mathrm{L}$. & CF 3806 & Arb \\
\hline & Vitex rufescens A.Juss & CF 3807 & Arv \\
\hline 44. Violaceae & Anchietea pyrifolia (Mart.) G.Don. * & CF 3808 & Tre \\
\hline
\end{tabular}

contrada em diversos estudos na América Tropical (Castellani 1986, Castellani \& Stubblebine 1993) e a segunda, encontrada como espécie de maior VI (valor de importância) por Oliveira (1999), numa capoeira de 5 anos de idade em mata de encosta na Reserva Biológica Estadual da Praia do Sul (RBEPS, Ilha Grande,RJ). Já em área de floresta de restinga submetida a corte raso sem destocamento há 25 anos (Assumpção \& Nascimento 2000), não foram encontradas tais pioneiras arbóreas, mas alta porcentagem de espécies (60\%) com capacidade de rebrota.

O estrato arbustivo apresentou 42 famílias de Angiospermas, distribuídas em 85 gêneros e 102 espécies (Tabela 1). As famílias mais ricas em espécies neste estrato foram: Leguminosae, Moraceae, Myrtaceae, Solanaceae e Bignoniaceae. As famílias Leguminosae e Myrtaceae, além disso, são as famílias que apresentaram o maior número de espécies na área de floresta de restinga adja-cente não perturbada (Sá \& Araújo, ined.). Matthes (1992), seis anos após o início da sucessão pós-fogo em Campinas/SP, encontrou as famílias Solanaceae, Myrtaceae, Rubiaceae, Rutaceae e Euphorbiaceae com maior número de espécies, e Rizzini (1978) já chamava atenção para a diversidade de espécies da família Solanaceae em áreas secundárias. Esta também foi bem representada na RBEPS em área floresta de encosta em regeneração há cinco anos (Oliveira 1999) e em floresta de restinga perturbada (Araújo et al. 1997), assim como a família Moraceae. No complexo lagunar GrussaíIquipari/RJ, Assumpção \& Nascimento (2000), encontraram Myrtaceae como a família lenhosa mais rica em espécies, seguida por Bromeliaceae, Cactaceae, Malpighiaceae e Orchidaceae.

A listagem geral do levantamento da área perturbada revelou 141 espécies, sendo 34\% 
das espécies comuns aos dois estratos indicados para a área por Sá (1993). Um levantamento bibliográfico sobre 110 táxons revelou que cerca de $19 \%$ são exclusivamente de ambientes secundários, sendo mais de 50\% dessas espécies distribuídas nas restingas e na mata atlântica. Na floresta de restinga perturbada da RBEPS a diversidade de espécies foi baixa (18 spp), sendo seis espécies de ambientes secundários e, de acordo com Araújo et al. (1997), a baixa diversidade na RBEPS e a alta diversidade da REEJ podem estar relacionadas a histórico de perturbações, idade dos cordões arenosos e tamanho das clareiras formadas. $\mathrm{Na}$ floresta de encosta da RBEPS em distintos estágios successionais 5, 25, 50 anos e climácica, Oliveira (1999) encontrou respectivamente 26 spp, 70 spp, 63 spp e 134 spp. Em GrussaíIquipari/RJ, Assumpção \& Nascimento (2000) encontraram 61 espécies na floresta de restinga (37 spp no inventário), sendo as cinco espécies dominantes atualmente (Maytenus obtusifolia, Pera glabrata, Protium heptaphyllum, Coccoloba alnifolia e Capparis flexuosa), fortemente relacionadas ao histórico de perturbação (corte raso sem destocamento). Os autores comentam também que a composição florística da floresta de restinga parece estar relacionada com as formações florestais adjacentes - mata de baixada e a mata de tabuleiro, já bastante raras e empobrecidas.

Apesar da largura das clareiras da REEJ ser maior que a da RBEPS, apenas dois indivíduos de Cecropia foram lá encontrados. Hartshorn (1980), aponta que diferentes espécies pioneiras são limitadas pelo tamanho da clareira formada, mencionando que espécies de Cecropia estão completamente ausentes em clareiras inferiores a $400 \mathrm{~m}^{2} . \mathrm{Na}$ RBEPS, Araújo et al. (1997) encontraram na floresta de restinga duas espécies Cecropia lyratiloba e Cecropia glaziovii entre as 3 espécies mais importantes da amostragem estrutural, e na mata de encosta abandonada há 5 anos, e Oliveira (1999) encontrou Cecropia lyratiloba como terceira espécie de maior VI. É possível que a importância dessas espécies na RBEPS estejam relacionadas à pouca largura do cordão arenoso e proximidade de fonte de propágulos; ao histórico uso de áreas de encosta para práticas agrícolas tradicionais (coivaras), que transformam a floresta num mosaico de florestas secundárias de idades distintas (Oliveira \& Coelho Neto 1996), e também pela forma da clareira na restinga (estrada extensa e estreita). Na REEJ, o cordão arenoso interno, onde está situada a floresta, é muito mais largo que o da Praia do Sul e, portanto, mais antigo e distanciado dos locais onde se realizam práticas agrícolas tradicionais (potenciais fontes de propágulos), embora as clareiras da REEJ sejam bem mais iluminadas que na RBEPS (Araújo et al. 1997).

\section{Estrutura}

As florestas de restinga da REEJ (este estudo) e da RBEPS (Araújo et al. 1997) são muito distintas quanto a estrutura e florística nas áreas não perturbadas e pertur-badas (Tabela 2). A área de Grussaí-Iquipari perturbada (Assumpção \& Nascimento 2000) apresenta valores muito díspares da REEJ e RBEPS para densidade e dominância. Araújo et al. (1997) referem-se à idade do cordão arenoso e histórico das perturbações como fatores que podem estar influenciando nas diferenças entre a REEJ e a RBEPS, sendo que em Grussaí-Iquipari (Assumpção \& Nascimento 2000) deve ser considerado o fator histórico, principalmente a idade (25 anos) e o tipo da perturbação (corte raso sem destocamento).

A altura média do estrato arbustivo na REEJ perturbada foi de $2,38 \mathrm{~m}$, bem menor que a da RBEPS, 4,3 m. As alturas de todos os individuos da REEJ variaram de 0,20 a $7,50 \mathrm{~m}$, estando as maiores concentrações nas classes compreendidas entre 1,13 e 2,65 m (Fig. 2a). Em Grussaí-Iquipari, de acordo com Assumpção \& Nascimento (2000), as alturas estiveram concentradas entre duas classes: 2$3 \mathrm{~m}$ e 3 - $4 \mathrm{~m}$, com raros indivíduos alcançando $6 \mathrm{~m}$. A classe de diâmetro 3,7 cm (Fig. 2b) agrupou ca. de $60 \%$ dos indivíduos amostrados na REEJ, grande parte composta por espécies 
Tabela 2 - Comparação de alguns parâmetros entre floresta de restinga não perturbada e perturbada em REEJ (Saquarema/ RJ), RBEPS (Ilha Grande RJ) e Grussaí-Iquipari/RJ.

\begin{tabular}{|c|c|c|c|c|c|}
\hline & $\begin{array}{c}\text { REEJ } \\
\text { Não } \\
\text { Perturbada }^{(1)}\end{array}$ & $\begin{array}{c}\text { RBEPS } \\
\text { Não } \\
\text { Perturbada }^{(2)}\end{array}$ & $\begin{array}{c}\text { REEJ } \\
\text { Perturbada }^{(3)}\end{array}$ & $\begin{array}{c}\text { RBEPS } \\
\text { Perturbada }^{(2)}\end{array}$ & $\begin{array}{l}\text { IQUIPARI } \\
\text { Perturbada }^{(4)}\end{array}$ \\
\hline Número de espécies & 110 & 64 & 102 & 18 & 37 \\
\hline Densidade (ind./ha) & 1.680 & 2.560 & 2.765 & 1.400 & 4.222 \\
\hline Dominância $\left(\mathrm{m}^{2} / \mathrm{ha}\right)$ & 24,81 & 25,9 & 11,92 & 3,51 & 32,66 \\
\hline Troncos múltiplos (\%) & 13 & 29,7 & 9,2 & 25,7 & 24 \\
\hline Altura média (m) & 8 & 5,2 & 2,38 & 4,3 & - \\
\hline
\end{tabular}

${ }^{(1)}$ Sá \& Araújo (ined.), (2) Araújo et al 1997, (3)Sá 1993 e ${ }^{(4)}$ Assumpção \& Nascimento (2000)

abundantes e o DAS médio foi de 5,94 cm. Já em Grussaí-Iquipari, a maioria dos indivíduos amostrados foi da classe entre 2,5 e $5,0 \mathrm{~cm}$ de diâmetro e, na restinga da RBEPS 50\%, dos diâmetros dos indivíduos ficaram concentrados na menor classe. De acordo com White (1980 apud Matthes 1992), para as espécies pioneiras não há uma relação entre o diâmetro do tronco e a idade da planta, mas com o vigor dos indivíduos.

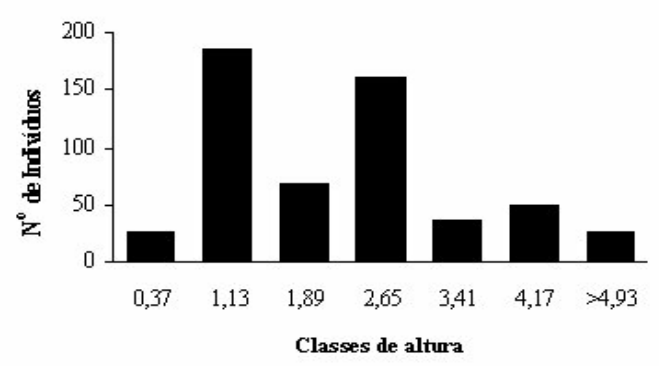

Figura 2a - Classes de altura (metro) para todos os indivíduos da área arbustiva da REEJ.

Dos 553 indivíduos amostrados neste estudo, $50 \%$ pertencem às 10 primeiras espécies (Tabela 3) que também acumulam $52 \%$ do VI. As espécies mais importantes em valores de VI Trema micrantha e Aegiphila sellowiana também são as mais abundantes (305 indiv./ha e 335 indiv./ha), representam $23 \%$ de todos os indivíduos desta formação e ocorrem, respectivamente, em 41 e $35 \%$ de

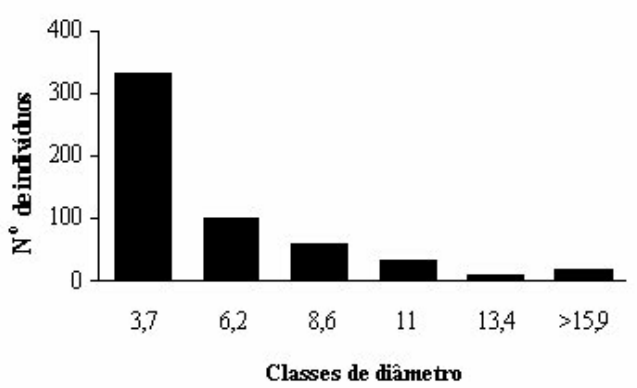

Figura 2b - Classes de diâmetro (centímetro) para todos os indivíduos da área arbustiva da REEJ.

todas as parcelas, concentrando $22,7 \%$ do VI. $\mathrm{Na}$ floresta de restinga da RBEPS (Araújo et al. 1997), essas espécies não foram encontradas, embora lá sejam encontradas em áreas secundárias (Trema micrantha - 5 anos, Aegiphila sellowiana - 5 anos e climácica) de floresta de encosta (Oliveira 1999). Trema micrantha também foi a espécie mais importante em área de mata semidecídua seis anos após perturbação por fogo Matthes (1992).

$\mathrm{Na}$ área da floresta não perturbada da REEJ, utilizando o método de quadrantes numa amostragem de 200 pontos (800 árvores) e com DAP $\geq 5 \mathrm{~cm}$ (Sá \& Araújo, inéd.), encontrouse apenas um indivíduo de Byrsonima sericea, com densidade de 2 indiv./ha e dominância de $0,05 \mathrm{~m}^{2} / \mathrm{ha}$, entretanto, na área perturbada, a densidade foi de 85 indiv./ha e a dominância de $1,2 \mathrm{~m}^{2} /$ ha, figurando entre as 5 espécies mais importantes da amostragem, o que demonstra um favorecimento a perturbação. Na RBEPS, 
Araújo et al. (1997) encontraram esta espécie como a mais importante na amostragem da área perturbada acumulando $45 \%$ do VI total, com densidade de 680 indiv./ha e dominância de $2,1 \mathrm{~m}^{2} / \mathrm{ha}$; para a floresta não perturbada apresentou densidade de 67 indiv./ha e dominância de $2,23 \mathrm{~m}^{2} / \mathrm{ha}$. Esta espécie também foi referenciada por Araújo \& Peixoto (1977) como dominante em área de restinga perturbada por fogo. Este favorecimento à perturbação indica comportamento de espécie pioneira, sendo sugerido por Araújo et al (1997) tratar-se de uma pioneira de vida longa. Assumpção \& Nascimento (2000) também encontraram Byrsonima sericea em baixa densidade e dominância em floresta de restinga após 25 anos da perturbação (corte raso), o que fortalece ainda mais esta condição. O mesmo comportamento é apresentado na floresta de encosta da RBEPS porAegiphila sellowiana (Oliveira 1999) que exibe alta densidade e maiores valores de VI em capoeira de 5 anos e em área climácica apresenta-se como espécie rara.

A arvoreta Brosimum guianense apresentou na área perturbada da REEJ densidade de 110 indiv./ha e VI de 3,2 \%, e na área da floresta não perturbada a densidade foi de 46 indiv./ha com VI de 2,1\% (Sá \& Araújo, dados não publicados). Apesar de não ter figurado na área da restinga da RBEPS, aparece significativamente em área de mata de encosta perturbada há 25 anos (Oliveira 1999) com alto valor de VI. Na floresta não perturbada, Sá \& Araújo (loc.cit) encontraram em Algernonia obovata o maior valor de VI $(7,2 \%)$ e densidade 145 indiv/ha, e neste estudo apresentou baixos valores em densidade (10 indiv./ha) e VI (0,39\%). Já Pterocarpus rohrii, o segundo maior valor de densidade na mata não perturbada (115 indiv/ha) e VI $(6,7 \%)$, apresentou na área perturbada densidade de 35 indiv./ha e $2,4 \%$ de VI, demonstrando desfavorecimento com a perturbação.

Três espécies de trepadeiras Bougainvillea spectabilis, Trigonia villosa e Eupatorium lundianum - estão entre as 10 espécies de maior VI, perfazendo $10 \%$ do VI total e foram bastante importantes no estrato herbáceo desta área (Sá 1996) com elevados valores de VI e IC. As duas primeiras apresentaram densidade de 135 e 125 indiv./ha, respectivamente. Estas espécies não foram amostradas na floresta não perturbada da REEJ por Sá \& Araújo (dados não publicados), em função da limitação do método, embora lá as trepadeiras sejam uma importante forma de vida (Sá 1992). Em Iquipari/RJ, de acordo com Assumpção \& Nascimento (2000), Coccoloba alnifolia e Capparis flexuosa, espécies de hábitos escandentes, estão entre as cinco espécies mais importantes de VI, a primeira apresentando $15 \%$ do total de indivíduos perfilhados.

Pterocarpus rohrii está associada a troncos múltiplos dentro da floresta não perturbada da REEJ, certamente devido à exploração da madeira por habitantes do entorno da área. Quatro das 10 espécies mais importantes em VI na floresta adjacente (Algernonia obovata, Guapira opposita, Simaba cuneata e Astronium graveolens) são pouco significativas no estrato arbustivo da área perturbada, demonstrando serem desfavorecidas com a perturbação. Experimentos silviculturais realizados na Malásia evidenciaram uma grande amplitude de respostas de algumas espécies a aberturas de clareiras em florestas de Dipterocarpaceae, onde algumas espécies têm seu crescimento acelerado e outras começam a atrofiar, tornando-se susceptíveis a doenças e predação ou morrem (Whitmore 1982 apud Finegan 1984).

Os resultados deste estudo comparado aos de Mattes (1992) revela as seguintes espécies arbóreas comuns: Trema micrantha, Astronium graveolens, Aegiphila sellowiana e Guapira opposita, chamando atenção o fato de Astronium graveolens ter se apresentado entre as dez espécies de maior VI na área de floresta não perturbada (Sá \& Araújo, ined.) e na área perturbada teve pouca importância, o que evidencia um desfavorecimento dessa espécie em relação à perturbação. Mattes (1992) verificou um aumento populacional de Astronium graveolens entre 1984 e 1987 em 
Tabela 3 - Parâmetros Fitossociológicos para o estrato arbustivo (DAS $\geq 2,5 \mathrm{~cm}$ ) da área de floresta de restinga perturbada por tratores na Reserva Ecologica Estadual de Jacarepia/RJ. $\mathrm{N}=$ no de individuos, $\mathrm{P}=\mathrm{n}^{\mathrm{O}}$ de parcelas com a especie, $\mathrm{AB}=$ área basal da sp, $\mathrm{DA}=$ densidade absoluta, $\mathrm{DR}=$ densidade relativa, $\mathrm{FA}=$ freqüência absoluta, $\mathrm{FR}=$ freqüência relativa, $\mathrm{DOA}=$ dominância absoluta, $\mathrm{DOR}=$ dominância relativa, $\mathrm{VI}=$ =valor de importância, $\mathrm{VC}=$ valor de cobertura.

\begin{tabular}{|c|c|c|c|c|c|c|c|c|c|c|c|c|c|}
\hline & Espécie & $\mathrm{N}$ & $\mathrm{P}$ & $\begin{array}{l}\mathrm{AB} \\
\mathrm{m}^{2} \\
\end{array}$ & $\mathrm{DA}$ & DR & FA & FR & $\begin{array}{l}\text { DOA } \\
\mathrm{m}^{2} / \mathrm{ha}\end{array}$ & DOR & VI & $\mathrm{VC}$ & $\overline{\mathrm{VI} \%}$ \\
\hline 1 & Trema micrantha & 61 & 33 & 0,426 & 305 & 11,03 & 41,25 & 8,66 & 2,13 & 17,86 & 37,56 & 28,89 & 12,5 \\
\hline 2 & Aegiphila sellowiana & 67 & 28 & 0,2663 & 335 & 12,12 & 35,00 & 7,35 & 1,332 & 11,17 & 30,63 & 23,28 & 10,2 \\
\hline 3 & Cestrum laevigatum & 19 & 12 & 0,2871 & 95 & 3,43 & 15,00 & 3,15 & 1,435 & 12,04 & 18,62 & 15,47 & 6,21 \\
\hline 4 & Byrsonima sericea & 17 & 9 & 0,2396 & 85 & 3,07 & 11,25 & 2,36 & 1,198 & 10,05 & 15,48 & 13,12 & 5,16 \\
\hline 5 & Bougainvillea spectabilis & 27 & 11 & 0,106 & 135 & 4,88 & 13,75 & 2,89 & 0,53 & 4,44 & 12,21 & 9,33 & 4,07 \\
\hline 6 & Trigonia villosa & 25 & 18 & 0,0312 & 125 & 4,52 & 22,50 & 4,72 & 0,156 & 1,31 & 10,55 & 5,83 & 3,52 \\
\hline 7 & Brosimum guianense & 22 & 16 & 0,0349 & 110 & 3,98 & 20,00 & 4,20 & 0,174 & 1,46 & 9,64 & 5,44 & 3,21 \\
\hline 8 & Cordia verbenacea & 16 & 12 & 0,0356 & 80 & 2,89 & 15,00 & 3,15 & 0,178 & 1,49 & 7,53 & 4,39 & 2,51 \\
\hline 9 & Pterocarpus rohrii & 7 & 5 & 0,1135 & 35 & 1,27 & 6,25 & 1,31 & 0,568 & 4,76 & 7,34 & 6,03 & 2,45 \\
\hline 10 & Eupatorium lundianum & 16 & 12 & 0,0263 & 80 & 2,89 & 15,00 & 3,15 & 0,132 & 1,10 & 7,15 & 4,00 & 2,38 \\
\hline 11 & Manihot aff tripartita & 19 & 12 & 0,0125 & 95 & 3,44 & 15,00 & 3,15 & 0,063 & 0,52 & 7,11 & 3,96 & 2,37 \\
\hline 12 & Solanum paniculatum & 17 & 10 & 0,0149 & 85 & 3,07 & 12,50 & 2,62 & 0,075 & 0,62 & 6,32 & 3,70 & 2,11 \\
\hline 13 & Pouteria grandiflora & 14 & 10 & 0,0278 & 70 & 2,53 & 12,50 & 2,62 & 0,139 & 1,17 & 6,32 & 3,70 & 2,11 \\
\hline 14 & Peschiera laeta & 13 & 10 & 0,0277 & 65 & 2,35 & 12,50 & 2,62 & 0,138 & 1,16 & 6,14 & 3,51 & 2,05 \\
\hline 15 & Solanum subscandens & 8 & 8 & 0,0327 & 40 & 1,45 & 10,00 & 2,10 & 0,163 & 1,37 & 4,92 & 2,82 & 1,64 \\
\hline 16 & Solanum sp & 10 & 9 & 0,0155 & 50 & 1,81 & 11,25 & 2,36 & 0,078 & 0,65 & 4,82 & 2,46 & 1,61 \\
\hline 17 & Ficus spl & 2 & 2 & 0,0919 & 10 & 0,36 & 2,50 & 0,52 & 0,46 & 3,85 & 4,74 & 4,22 & 1,58 \\
\hline 18 & Guettarda viburnoides & 12 & 5 & 0,0222 & 60 & 2,17 & 6,25 & 1,31 & 0,111 & 0,93 & 4,41 & 3,10 & 1,47 \\
\hline 19 & Macfadyena sp & 9 & 7 & 0,0113 & 45 & 1,63 & 8,75 & 1,84 & 0,056 & 0,47 & 3,94 & 2,10 & 1,31 \\
\hline 20 & Ficus hirsuta & 1 & 1 & 0,0707 & 5 & 0,18 & 1,25 & 0,26 & 0,353 & 2,96 & 3,41 & 3,14 & 1,14 \\
\hline 21 & Machaerium pedicellatum & 5 & 4 & 0,0324 & 25 & 0,90 & 5,00 & 1,05 & 0,162 & 1,36 & 3,31 & 2,26 & 1,1 \\
\hline 22 & Connarus nodosus & 7 & 6 & 0,0083 & 35 & 1,27 & 7,50 & 1,57 & 0,041 & 0,35 & 3,19 & 1,61 & 1,06 \\
\hline 23 & Machaerium hirtum & 5 & 5 & 0,0222 & 25 & 0,90 & 6,25 & 1,31 & 0,111 & 0,93 & 3,15 & 1,84 & 1,05 \\
\hline 24 & Solanum inaequale & 2 & 2 & 0,0487 & 10 & 0,36 & 2,50 & 0,52 & 0,244 & 2,04 & 2,93 & 2,41 & 0,98 \\
\hline 25 & Matayba guianensis & 5 & 3 & 0,0234 & 25 & 0,90 & 3,75 & 0,79 & 0,117 & 0,98 & 2,67 & 1,89 & 0,89 \\
\hline 26 & Ficus citrifolia & 2 & 2 & 0,0372 & 10 & 0,36 & 2,50 & 0,52 & 0,186 & 1,56 & 2,45 & 1,92 & 0,82 \\
\hline 27 & Strychnos parvifolia & 5 & 5 & 0,0055 & 25 & 0,90 & 6,25 & 1,31 & 0,027 & 0,23 & 2,45 & 1,13 & 0,82 \\
\hline 28 & Ruprechtia lundii & 4 & 4 & 0,0153 & 20 & 0,72 & 5,00 & 1,05 & 0,076 & 0,64 & 2,41 & 1,36 & 0,8 \\
\hline 29 & Croton hemiargyreus & 9 & 1 & 0,0123 & 45 & 1,63 & 1,25 & 0,26 & 0,062 & 0,52 & 2,41 & 2,14 & 0,8 \\
\hline 30 & Inga maritima & 6 & 3 & 0,0092 & 30 & 1,08 & 3,75 & 0,79 & 0,046 & 0,38 & 2,26 & 1,47 & 0,75 \\
\hline 31 & Albizia polycephala & 5 & 4 & 0,0064 & 25 & 0,90 & 5,00 & 1,05 & 0,032 & 0,27 & 2,22 & 1,17 & 0,74 \\
\hline 32 & Swartzia apetala & 4 & 4 & 0,004 & 20 & 0,72 & 5,00 & 1,05 & 0,02 & 0,17 & 1,94 & 0,89 & 0,65 \\
\hline 33 & Opuntia brasiliensis & 3 & 3 & 0,0115 & 15 & 0,54 & 3,75 & 0,79 & 0,058 & 0,48 & 1,81 & 1,02 & 0,60 \\
\hline 34 & Hippocratea volubilis & 4 & 3 & 0,0063 & 20 & 0,72 & 3,75 & 0,79 & 0,031 & 0,26 & 1,77 & 0,99 & 0,59 \\
\hline 35 & Vitex rufescens & 3 & 3 & 0,0096 & 15 & 0,54 & 3,75 & 0,79 & 0,048 & 0,40 & 1,73 & 0,94 & 0,58 \\
\hline 36 & Indet. 2 & 1 & 1 & 0,0301 & 5 & 0,18 & 1,25 & 0,26 & 0,151 & 1,26 & 1,71 & 1,44 & 0,57 \\
\hline 37 & Salacia arborea & 4 & 3 & 0,0045 & 20 & 0,72 & 3,75 & 0,79 & 0,022 & 0,19 & 1,70 & 0,91 & 0,57 \\
\hline 38 & Annona acutiflora & 4 & 3 & 0,0038 & 20 & 0,72 & 3,75 & 0,79 & 0,019 & 0,16 & 1,67 & 0,88 & 0,56 \\
\hline 39 & Guapira sp & 3 & 3 & 0,0057 & 15 & 0,54 & 3,75 & 0,79 & 0,029 & 0,24 & 1,57 & 0,78 & 0,52 \\
\hline 40 & Manilkara subsericea & 3 & 3 & 0,0044 & 15 & 0,54 & 3,75 & 0,79 & 0,022 & 0,19 & 1,52 & 0,73 & 0,51 \\
\hline 41 & Coccoloba arborescens & 3 & 3 & 0,0035 & 15 & 0,54 & 3,75 & 0,79 & 0,018 & 0,15 & 1,48 & 0,69 & 0,49 \\
\hline 42 & Paullinia racemosa & 3 & 3 & 0,0028 & 15 & 0,54 & 3,75 & 0,79 & 0,014 & 0,12 & 1,45 & 0,66 & 0,48 \\
\hline 43 & Pilosocereus arrabidae & 3 & 3 & 0,0024 & 15 & 0,54 & 3,75 & 0,79 & 0,012 & 0,10 & 1,43 & 0,64 & 0,48 \\
\hline 44 & Anchietea pyrifolia & 2 & 2 & 0,0088 & 10 & 0,36 & 2,50 & 0,52 & 0,044 & 0,37 & 1,26 & 0,73 & 0,42 \\
\hline 45 & Eupatorium maximilianii & 2 & 2 & 0,0078 & 10 & 0,36 & 2,50 & 0,52 & 0,039 & 0,33 & 1,21 & 0,69 & 0,4 \\
\hline 46 & Poecilanthe falcata & 2 & 2 & 0,0072 & 10 & 0,36 & 2,50 & 0,52 & 0,036 & 0,30 & 1,19 & 0,66 & 0,4 \\
\hline 47 & Algernonia obovata & 2 & 2 & 0,0067 & 10 & 0,36 & 2,50 & 0,52 & 0,034 & 0,28 & 1,17 & 0,64 & 0,39 \\
\hline 48 & Cecropia sp & 2 & 2 & 0,0063 & 10 & 0,36 & 2,50 & 0,52 & 0,031 & 0,26 & 1,15 & 0,62 & 0,38 \\
\hline 49 & Adenocalymma trifoliatum & 3 & 2 & 0,0016 & 15 & 0,54 & 2,50 & 0,52 & 0,008 & 0,07 & 1,14 & 0,61 & 0,38 \\
\hline 50 & Aspidosperma parvifolium & 2 & 2 & 0,0056 & 10 & 0,36 & 2,50 & 0,52 & 0,028 & 0,23 & 1,12 & 0,59 & 0,37 \\
\hline 51 & Leretia cordata & 2 & 2 & 0,0046 & 10 & 0,36 & 2,50 & 0,52 & 0,023 & 0,19 & 1,08 & 0,55 & 0,36 \\
\hline
\end{tabular}


Regeneração de um trecho de floresta de restinga na Reserva Ecológica Estadual de Jacarepiá,

Saquarema, Estado do Rio de Janeiro: II - Estrato arbustivo

\begin{tabular}{|c|c|c|c|c|c|c|c|c|c|c|c|c|c|}
\hline & Espécie & $\mathrm{N}$ & $\mathrm{P}$ & $\begin{array}{c}\mathrm{AB} \\
\mathrm{m}^{2}\end{array}$ & DA & DR & FA & FR & $\begin{array}{l}\text { DOA } \\
\mathrm{m}^{2} / \mathrm{ha}\end{array}$ & DOR & VI & $\mathrm{VC}$ & $\mathrm{VI} \%$ \\
\hline 52 & Seguiera americana & 2 & 2 & 0,0045 & 10 & 0,36 & 2,50 & 0,52 & 0,022 & 0,19 & 1,08 & 0,55 & 0,36 \\
\hline 53 & Psychotria aff brachyceras & 2 & 2 & 0,0035 & 10 & 0,36 & 2,50 & 0,52 & 0,018 & 0,15 & 1,03 & 0,51 & 0,34 \\
\hline 54 & Tournefortia menbranacea & 2 & 2 & 0,0031 & 10 & 0,36 & 2,50 & 0,52 & 0,016 & 0,13 & 1,02 & 0,49 & 0,34 \\
\hline 55 & Pouteria reticulata & 1 & 1 & 0,0134 & 5 & 0,18 & 1,25 & 0,26 & 0,067 & 0,56 & 1,0 & 0,74 & 0,33 \\
\hline 56 & Allophyllus puberulus & 2 & 2 & 0,0027 & 10 & 0,36 & 2,50 & 0,52 & 0,013 & 0,11 & 1,0 & 0,47 & 0,33 \\
\hline 57 & Ouratea cuspidata & 2 & 2 & 0,0021 & 10 & 0,36 & 2,50 & 0,52 & 0,011 & 0,09 & 0,97 & 0,45 & 0,32 \\
\hline 58 & Mimosa ceratonia & 2 & 2 & 0,0019 & 10 & 0,36 & 2,50 & 0,52 & 0,01 & 0,08 & 0,97 & 0,44 & 0,32 \\
\hline 59 & Staelia thymoides & 2 & 2 & 0,0013 & 10 & 0,36 & 2,50 & 0,52 & 0,007 & 0,05 & 0,94 & 0,42 & 0,31 \\
\hline 60 & Indet.4 & 2 & 2 & 0,0013 & 10 & 0,36 & 2,50 & 0,52 & 0,006 & 0,05 & & 0,42 & 0,31 \\
\hline 61 & Solanum aturense & 2 & 2 & 0,0012 & 10 & 0,36 & 2,50 & 0,52 & 0,006 & 0,05 & 0,94 & 0,41 & 0,31 \\
\hline 62 & Schinus terebinthifolius & 2 & 2 & 0,001 & 10 & 0,36 & 2,50 & 0,52 & 0,005 & 0,04 & 0,93 & 0,40 & 0,31 \\
\hline 63 & Machaerium lanceolatum & 1 & 1 & 0,01 & 5 & 0,18 & 1,25 & 0,26 & 0,05 & 0,42 & 0,86 & 0,60 & 0,29 \\
\hline 64 & Cordia superba & 1 & 1 & 0,008 & 5 & 0,18 & 1,25 & 0,26 & 0,04 & 0,34 & 0,78 & 0,52 & 0,26 \\
\hline 65 & Simaba cuneata & 1 & 1 & 0,0 & 5 & & & 0,26 & & 30 & & 48 & 0,25 \\
\hline 66 & Celtis sp & 1 & 1 & 0,0062 & 5 & 0,18 & 1,25 & 0,26 & 0,031 & 0,26 & 0,71 & 0,44 & 0,24 \\
\hline 67 & Marlierea schotti & 1 & 1 & 0,0044 & 5 & 0,18 & 1,25 & 0,26 & 0,022 & 0,19 & 0,63 & 0,37 & 0,21 \\
\hline 68 & Ocotea sp & 1 & 1 & 0,0042 & 5 & 0,18 & 1,25 & 0,26 & 0,021 & 0,18 & 0,62 & 0,36 & 0,21 \\
\hline 69 & Ocotea notata & 1 & 1 & 0,0042 & 5 & 0,18 & 1,25 & 0,26 & 0,021 & 0,18 & 0,62 & 0,36 & 0,21 \\
\hline 70 & Abutilon esculentum & 1 & 1 & 0,0039 & 5 & 0,18 & 1,25 & 0,26 & 0,019 & 0,16 & 0,6 & 0,34 & 0,20 \\
\hline 71 & Ficus clusiifolia & 1 & 1 & 0,00 & 5 & 0,18 & 1,25 & 0,26 & 0,016 & & & 0,31 & 0,19 \\
\hline 72 & Guapira opposita & 1 & 1 & 0,0032 & 5 & 0,18 & 1,25 & 0,26 & 0,016 & 0,13 & 0,58 & 0,31 & 0,19 \\
\hline 73 & Bombacopsis stenopetala & 1 & 1 & 0,0032 & 5 & 0,18 & 1,25 & 0,26 & 0,016 & 0,13 & 0 , & 0,31 & 0,19 \\
\hline 74 & Ficus sp2 & 1 & 1 & 0,0026 & 5 & 0,18 & 1,25 & 0,26 & 0,013 & 0,11 & 0,55 & 29 & 0,18 \\
\hline 75 & Indet. 1 & 1 & 1 & 0,0026 & 5 & 0,18 & 1,25 & 0,26 & 0,013 & 0,11 & 0,55 & 0,29 & 0,18 \\
\hline 76 & Chondrodendrum platyphyllum & 1 & 1 & 0,0023 & 5 & 0,18 & 1,25 & 0,26 & 0,012 & 0,10 & 0,54 & 0,28 & 0,18 \\
\hline 77 & Indet.5 & 1 & 1 & 0,0022 & 5 & 0,18 & 1,25 & 0,26 & 0,011 & 0,09 & 0,53 & 0,27 & 0,18 \\
\hline 78 & Casearia aff decandra & 1 & 1 & 0,0022 & 5 & 0,18 & 1,25 & 0,26 & 0,011 & 0,09 & 0 , & 0,27 & 0,18 \\
\hline 79 & Pereskia aculeata & 1 & 1 & 0,002 & 5 & 0,18 & 1,25 & 0,26 & 0,01 & 0,09 & 0,53 & 0,27 & 0,18 \\
\hline 80 & Aureliana fasciculata & 1 & 1 & 0,002 & 5 & 0,18 & 1,25 & 0,26 & 0,01 & 0,09 & 0,53 & 0,27 & 0,18 \\
\hline 81 & Myrtaceae Indet. 2 & 1 & 1 & 0,0019 & 5 & 0,18 & 1,25 & 0,26 & 0,01 & 0,08 & 0,52 & 0,26 & 0,17 \\
\hline 82 & Pilocarpus spicatus & 1 & 1 & 0,0016 & 5 & 0,18 & 1,25 & 0,26 & 0,008 & 0,07 & 0 & 0,25 & 0,17 \\
\hline 83 & Paullinia weinmaniaefolia & 1 & 1 & 0,0015 & 5 & 0,18 & 1,25 & 0,26 & 0,007 & 0,06 & 0 & 0,24 & 0,17 \\
\hline 84 & Myrtaceae Indet. 1 & 1 & 1 & 0,0014 & 5 & 0,18 & 1,25 & 0,26 & 0,007 & 0,06 & 0 , & 0,24 & 0,17 \\
\hline 85 & Capparis flexuo & 1 & 1 & 0,00 & 5 & & 1 , & 0,26 & & 0,06 & 0 & 0,24 & 0,17 \\
\hline 86 & Sorocea hilarii & 1 & 1 & 0,0014 & 5 & 0,18 & 1,25 & 0,26 & 0,007 & 0,06 & 0,5 & 0,24 & 0,17 \\
\hline 87 & Parapiptadenia pterosperma & 1 & 1 & 0,0012 & 5 & 0,18 & 1,25 & 0,26 & 0,006 & 0,05 & 0,5 & 0,23 & 0,17 \\
\hline 88 & Casearia oblongifolia & 1 & 1 & 0,0012 & 5 & 0 & 1,25 & 0,26 & 0,006 & 0,05 & 0 , & 0,23 & 0,16 \\
\hline 89 & Myrtaceae Indet.3 & 1 & 1 & 0,0012 & 5 & 0,18 & 1,25 & 0,26 & 0,006 & 0,05 & 0,49 & 0,23 & 0,16 \\
\hline 90 & Eugenia repanda & 1 & 1 & 0,0011 & 5 & 0,18 & 1,25 & 0,26 & 0,005 & 0,04 & 0,49 & 0,22 & 0,16 \\
\hline 91 & Myrtaceae Indet. 4 & 1 & 1 & 0,001 & 5 & 0,18 & 1,25 & 0,26 & 0,005 & 0,04 & 0,48 & 0,22 & 0,16 \\
\hline 92 & Baccharis serrulata & 1 & 1 & 0,001 & 5 & 0,18 & 1,25 & 0,26 & 0,005 & 0,04 & 0,48 & 0,22 & 0,16 \\
\hline 93 & Chrysophyllum januariense & 1 & 1 & 0,001 & 5 & 0,18 & 1,25 & 0,26 & 0,005 & 0,04 & 0,48 & 0,22 & 0,16 \\
\hline 94 & Astronium graveolens & 1 & 1 & 0,001 & 5 & 0,18 & 1,25 & 0,26 & 0,005 & 0,04 & 0,48 & 0,22 & 0,16 \\
\hline 95 & Compositae Indet. 1 & 1 & 1 & 0,001 & 5 & 0,18 & 1,25 & 0,26 & 0,005 & 0,04 & 0,48 & 0,22 & 0,16 \\
\hline 96 & Clavija spinosa & 1 & 1 & 0,001 & 5 & 0,18 & 1,25 & 0,26 & 0,005 & 0,04 & 0,48 & 0,22 & 0,16 \\
\hline 97 & Calyptranthes sp & 1 & 1 & & 5 & 0,18 & & 0,26 & & & & 0,22 & 0,16 \\
\hline 98 & Amphilophium vauthieri & 1 & 1 & 0,0008 & 5 & 0,18 & 1,25 & 0,26 & 0,004 & 0,03 & 0,48 & 0,21 & 0,16 \\
\hline 99 & Indet. 3 & 1 & 1 & 0,0007 & 5 & 0,18 & 1,25 & 0,26 & 0,004 & 0,03 & 0,47 & 0,21 & 0,16 \\
\hline 100 & Arrabidaea conjugata & 1 & 1 & 0,0006 & 5 & 0,18 & 1,25 & 0,26 & & 0,03 & 0,47 & 0,21 & 0,16 \\
\hline 101 & Anartia oblongifolia & 1 & 1 & 0,0005 & 5 & 0,18 & 1,25 & 0,26 & 0,003 & 0,02 & 0,47 & 0,20 & 0,16 \\
\hline 102 & Lantana camara & 1 & 1 & 0,0005 & 5 & 0,18 & 1,25 & 0,26 & 0,003 & 0,02 & 0,46 & 0,20 & 0,15 \\
\hline & $\Sigma$ & 553 & & 2,3847 & 2765 & 100 & 476,25 & 100 & 11,92 & 100 & 300 & 200 & 100 \\
\hline
\end{tabular}


diferentes proporções para cada área submetida a diferentes intensidades de fogo. Em nosso estudo, podemos concluir que, entre as 10 espécies de maior VI, as arbóreas e arbustivas Trema micrantha, Byrsonima sericea, Aegiphila sellowiana, Cestrum laevigatum e Cordia verbenacea são as espécies pioneiras na área, e as secundárias são Brosimum guianense e Pterocarpus rohrii.

As florestas de restinga da Ilha Grande, Jacarepiá e Iquipari estão localizadas em pontos considerados até o momento limite de distribuição de muitas espécies, e são muito díspares em riqueza de espécies e no conhecimento de suas floras (Araújo 2000). De acordo com esta autora, até o momento, são conhecidas mais de 1.000 espécies de angiospermas para a flora das restingas fluminenses, e o contato com as formações vegetais próximas as restingas varia também ao longo do litoral. Tais fatores, associados à natureza das perturbações, fazem com que os padrões de regeneração das florestas de restinga no litoral fluminense exibam arranjos florísticos e estruturais diferenciados, como em GrussaíIquipari (Assumpção e Nascimento 2000), situada numa das mais extensas e pouco conhecidas áreas de restingas fluminenses, cujo histórico de ocupação e perturbações remonta a meados do século XVII, com a ocupação das planícies para a criação de gado (Soffiati 1996). Por exemplo, Pera glabrata foi encontrada em capoeira de 25 anos na RBEPS e como espécie climácica na floresta de encosta da RBEPS (Oliveira 1999), não foi encontrada na REEJ (este estudo), mas em GrussaíIquipari (Assumpção\& Nascimento 2000) é uma espécie característica, formando inclusive associações exclusivas com Bromelia antiacantha, que levaram os autores a considerar a região como um novo elemento no mosaico das restingas fluminenses.

\section{Limitações a regeneração, troncos múltiplos e trepadeiras}

Tem sido citado em geral que a regeneração em florestas de restinga no Estado do Rio de Janeiro é lenta (Sá 1996; Araújo et al. 1997, Gonçalves \& Sá 1998) e também variável entre restingas, pois o número de espécies surgidas e a recuperação de suas características estruturais depende do agente de perturbação, da intensidade do evento e da proximidade das fontes de propágulos. A afirmação se faz em função da natureza dos distúrbios ocorridos na REEJ e na RBEPS e das condições abióticas geradas, já que o nivelamento de áreas por tratores remove profundamente o solo e elimina fontes de rebrota (troncos, raízes), importante mecanismo na recomposição de ambientes perturbados (floresta atlântica - Oliveira 1999; restinga - Sá 1993, Araújo et al. 1997, Carvalhaes \& Mantowani 1998, Assumpção \& Nascimento 2000; caatinga Sampaio et al. 1998; floresta amazônica Uhl et al. 1988, Kauffman 1991). Deve-se também considerar que, em restingas, o solo apresenta pequeno conteúdo de nutrientes e o alto índice de escleromorfismo foliar acarreta baixa degradabilidade da serrapilheira acumulada, resultando em menor liberação e maior tempo de renovação de estoque (Moraes et al. 1998). De acordo com Whitmore (1990), a variação térmica constitui um dos fatores de inibição de processos biológicos e, além da luz e da temperatura, afetam a germinação das sementes o termoperíodo e a escarificação mecânica. Estes participam em maior ou menor grau do controle da vegetação que irá formar-se (Vazques Yanes 1976).

$\mathrm{Na}$ REEJ, a temperatura do solo variou $26,3^{\circ} \mathrm{C}$ em 11 horas de monitoramento (Fig. 3 ) em fevereiro de $02 / 02 / 1993$, atingindo às $14 \mathrm{~h}$ a temperatura máxima de $56,4^{\circ}$, a $5 \mathrm{~cm}$ de profundidade (Sá 1993). Este resultado está de acordo com Araújo et al. (1997), que encontraram na RBEPS, à mesma profundidade, a variação de $24^{\circ} \mathrm{C}$ em 12 horas de monitoramento em janeiro de 1991. Associe-se a este fato o uso de tratores no processo de desmatamento que reviram mais intensamente as camadas de solo, e são perturbações tão violentas que são comparadas às perturbações causadas por ciclones (Webb et 
al. 1972 apud Castellani 1986). A dificuldade de germinação e estabelecimento de espécies a partir da chuva de sementes das áreas próximas, principalmente as tolerantes, também foi observada por Araujo et al. (1997).

Além desses fatores, foi verificado por Moreno (1977) que sementes de regiões tropicais apresentam curta viabilidade e dormência (quando as tem), em relação às sementes de regiões temperadas. Plântulas e sementes são também afetadas pela disponibilidade de matéria orgânica acumulada sobre o solo, tendo em vista o incremento na retenção de umidade (Finegan 1984). Desta forma, moitas de trepadeiras e de pequenos arbustos em ambientes de restinga perturbados constituem um campo interessante para investigações de natureza prática e teórica, já que nestes locais há acúmulo de matéria orgânica, retenção de umidade e temperatura intermediária entre solo de áreas desnudas e áreas florestadas.

A instalação de sementes em áreas perturbadas de restinga somente foi verificada no trabalho de Araújo \& Peixoto (1977), onde ao longo de 36 meses de acompanhamento após fogo, somente espécies herbáceas se instalaram numa restinga arbustiva. Castellani (1986) observou na mata mesófila da Reserva da Fazenda Santa Genebra/SP que, 8 meses após o fogo, apenas as espécies arbóreas secundárias Trema micrantha, Jacaratia spinosa e Cecropia sp estabeleceram-se a partir de sementes. Matthes (1992), trabalhando na mesma área, concluiu que a vegetação da área queimada foi proveniente de sementes, do banco de sementes do solo e da rebrota de caule ou raízes subterrâneas; e que espécies pioneiras pareceram não colonizar a área através de rebrota. Embora seja um mecanismo fundamental no restabelecimento da vegetação, devido ao avançado estágio de regeneração na REEJ, foi impossível descobrir seis anos depois que espécies, exceto pioneiras como Trema micrantha, Aegiphila sellowiana entre outras, originaram-se a partir de rebrotas e de sementes. Entretanto, na REEJ, espécies como Pterocarpus rohrii e Pouteria grandiflora foram encontradas com altos índices de rebrota no estudo de uma clareira de 0,2 ha (Schneider, Sá \& Araújo, ined.) originada a partir do corte raso de árvores. Estas espécies têm alto VI na floresta não perturbada (Sá \& Araújo, ined.). No presente estudo, as mesmas espécies apresentaram altos valores de VI, especialmente a primeira.

Matthes (1992) observou, em área perturbada por fogo, 24 espécies, a maioria arbórea, cujos indivíduos, oriundos de rebrota,

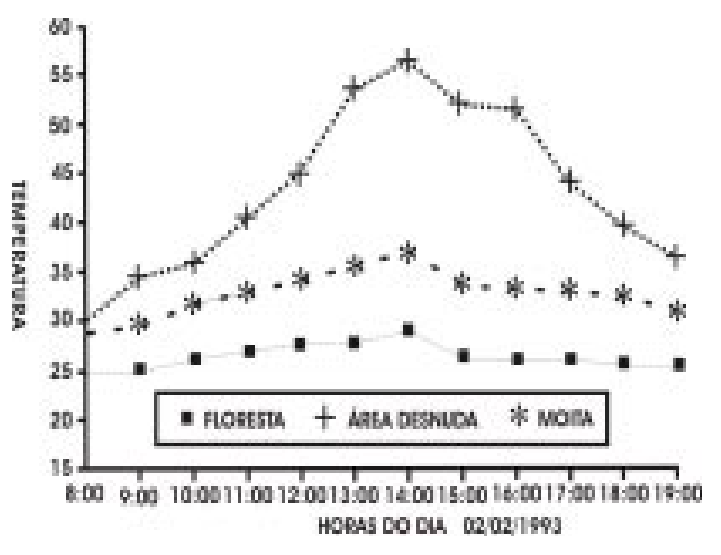

Figura 3 - Monitoramento da temperatura a $5 \mathrm{~cm}$ do solo em três áreas perturbadas da REEJ em 02/02/1993.

apresentavam troncos múltiplos ao nível do solo, enquanto indivíduos provenientes de sementes tinham um único tronco. Em Florestas de Restinga, parece ser relativamente comum indivíduos arbóreos com troncos múltiplos (obs. pess). Este comportamento foi notado nas florestas de restinga ocorrentes no Sul da Bahia (Nova Viçosa e Mucuri), Saquarema (RJ) e Barra dos Coqueiros (SE). Araújo (com. pess.) também constatou estas evidências em florestas de Restinga em Carapebus e Ilha Grande (RJ). Troncos múltiplos talvez possam, inclusive, sugerir um determinado grau de perturbação nestas florestas submetidas a cortes seletivos de árvores por habitantes próximos, já que Hueck (1972) salientava que a raridade dessas florestas estava associada às necessidades de lenha $e$ madeira de pescadores e habitantes das cida- 
des litorâneas. Entretanto, troncos múltiplos também podem estar relacionados à ausência de exploração da floresta, sendo assim uma característica da própria floresta e de determinadas espécies, como foi verificado por Dunphy et al. (2000) em Porto Rico.

No estrato arbustivo da área perturbada da REEJ, 9\% dos indivíduos apresentaram troncos múltiplos distribuídos em 26 espécies arbóreas, arbustivas ou trepadeiras. Também as 10 espécies de maior VI deste estrato apresentaram troncos múltiplos, principalmente Bougainvillea spectabilis, com $30 \%$ de seus indivíduos com troncos dessa forma. Dos 800 indivíduos arbóreos da amostragem de Sá \& Araújo (dados não publicados), $13 \%$ apresentaram troncos múltiplos. As espécies que apresentaram maior número de troncos múltiplos na mata não perturbada foram: Algernonia obovata, Pterocarpus rohrri, Simaba cuneata, Pouteria grandiflora, Pseudopiptadenia contorta, Lauraceae 1 e Alseis involuta. Na REEJ, Brosimum guianense figura entre as espécies mais representativas, 6 anos após distúrbio, parecendo este fato estar muito relacionado com a rebrota, e Pterocarpus rohrii apresentou-se como a segunda espécie de maior VI na floresta adjacente (Sá \& Araújo, dados não publicados) e também como uma das espécies que mais rebrotou numa área que sofreu corte raso situada próxima a nossa amostragem (Schneider, Sá \& Araújo ined.).

Carvalhaes \& Mantowani (1998) também atestaram a ocorrência de rebrotas e sua importância na regeneração da floresta de restinga da Juréia/SP. Na área da floresta de restinga de Iquipari, Assumpção \& Nascimento (2000) indicaram a importância das rebrotas na recomposição da floresta, já que cerca de $60 \%$ das espécies amostradas e $24 \%$ de todos os indivíduos amostrados apresentaram-se perfilhados. Os percentuais de rebrota em Iquipari e nas áreas não perturbadas e perturbadas da RBEPS (Tabela 2) são muito próximos, indicando sua influência na estrutura da nova floresta.
Um tronco múltiplo, geralmente originado a partir de rebrota, poder ser considerado uma vantajosa adaptação na conquista de espaço sobre outras plantas pois, de acordo com Grime (1979 apud Castellani 1986), Newel \& Tramer (1978), Kauffman (1991), indivíduos que se regeneram por rebrotas não têm que alocar recursos na formação de raízes, conferindo vantagem competitiva sobre as espécies que se instalam a partir de sementes.

Na REEJ, as trepadeiras são formas de vida muito importantes no estabelecimento de espécies tolerantes à sombra pelo fato de formarem moitas, verdadeiras ilhas, onde a temperatura é mais amena que nas áreas desnudas, e a serrapilheira aí depositada proporciona maior retenção de umidade e acúmulo de nutrientes (Sá 1993). O sucesso do estabelecimento de trepadeiras na área desnuda da REEJ deve seguramente estar relacionado à abundância com que as mesmas ocorrem naturalmente na floresta adjacente e nas bordas dos fragmentos deixados após a abertura dos arruamentos, conjugados com dispersão anemocórica. Trepadeiras em abundância são associadas a formações de matas secundárias muito jovens, tendo estas aspectos emaranhados (Richards 1952; Budowiski 1963, 1965, 1966), e Janzen (1980) observou a abundância das trepadeiras em áreas perturbadas e orlas de mata de regiões de florestas tropicais, bem como a rápida regeneração após roçadas e a presença de rizomas resistentes ao fogo e persistentes ao longo de etapas sucessionais.

Castellani (1986) evidenciou forte dominância de trepadeiras (36\% das espécies), tanto em cobertura como em biomassa nos estágios iniciais de sucessão na Reserva Municipal da Fazenda Santa Genebra em área perturbada por fogo. Após esse estágio inicial, o desenvolvimento de lianas acompanhou o crescimento das árvores e dos arbustos, tornando o estrato inferior gradativamente menos denso, o que também é observado nos locais onde há menor incidência de trepadeiras herbáceas. Matthes (1992) observou na 
mesma área uma grande porcentagem de árvores com lianas, entre as espécies consideradas e entre os tipos de parcelas (fogo intenso, médio, sem fogo), não verificando nenhum padrão de preferência das trepadeiras por espécies sustentadoras. Relaciona também que a sobrecarga de biomassa das lianas associadas aos fortes ventos acarreta a inclinação e quebra do fuste ou galhos, ou, ainda, a morte dos indivíduos arbóreos. A forma de crescimento de Bougainvillea spectabilis e de outras espécies de trepadeiras na REEJ que formam emaranhados sobre arbustos e árvores jovens, nos faz lembrar a observação daquele autor a respeito de Celtis iguanea. $\mathrm{O}$ mesmo comenta que indivíduos desta espécie, que também se comportam como trepadeiras, podem representar um ponto de estrangulamento no crescimento das espécies arbóreas pioneiras e até mesmo segurar ou reverter o processo sucessional, devendo-se a este fato o rápido crescimento de suas ramas, que, por necessitarem suporte, acabam por sufocar indivíduos arbóreos e arbustivos.

Na região de Piracicaba (SP), a elevada dominância de cipós foi associada a uma baixa densidade de regeneração natural de espécies arbóreas (Viana et al. 1992), tendo o autor salientando que, no manejo conservacionista, deve ser mantida parte destas formas de vida. No caso da REEJ, ao mesmo tempo que podem ser consideradas um bom indicador de perturbação da floresta adjacente, estas formas de vida podem refletir também uma característica desta floresta (Sá 1992). As trepadeiras na área perturbada vem propiciando, ao longo desses anos, um considerável acúmulo de matéria orgânica sobre o solo, bem como têm recoberto com suas extensas ramificações áreas mais internas de determinados arruamentos. Assim sendo, a abundância das trepadeiras na REEJ deve ser analisada com muita cautela ao enfocá-las como formas de vida que segurariam o processo sucessional, como encontrado por Matthes (1992) em Campinas/SP.

Apesar da área da REEJ estar situada numa unidade de conservação, ainda há diver- sos agentes de perturbação atuando, o que dificulta ainda mais o processo de regeneração natural. $\mathrm{O}$ estudo dinâmico da regeneração natural de áreas de restinga perturbadas em suas diferentes comunidades é uma interessante estratégia para entender os processos e por quanto tempo atuam num ambiente tão complexo. Desta forma, os trabalhos desenvolvidos na RBEPS (Araújo et al. 1997) e na REEJ (Sá 1993, 1996; Gonçalves \& Sá 1998) indicam uma lenta regeneração das florestas de restinga em áreas severamente degradadas em função do histórico da perturbação nas condições edáficas, composição florística e estrutura. Trabalhos desta natureza também são fundamentais para subsidiar e orientar o Ministério Público na solicitação de reparação de danos causados neste ecossistema. A pressão para ocupação dessas áreas por atividades turísticas e comerciais em centros urbanos litorâneos tem gerado severos impactos propositais, para que em juízo medidas compensatórias sejam propostas, negociadas e implementadas fora das áreas objeto da ação (na periferia ou mesmo em outro local).

\section{AGRADECIMENTOS}

Ao Conselho Nacional de Desenvolvimento Científico e Tecnológico - CNPq pela bolsa concedida durante a realização do curso. À Dra. Graziela Maciel Barroso e à Profa. Dorothy Sue Dunn de Araujo por toda a orientação e atenção. Ao Dr. Paulo Y. Kageyama, à Dra. Ariane L.Peixoto e ao Prof. Rogério Ribeiro de Oliveira pelo exame e sugestões na dissertação. A todos os botânicos do JBRJ, da UFRJ e do Museu Nacional, que auxiliaram nas identificações do material coletado. A Marcos Antônio de Oliveira e Jorge Caruso Gomes nos trabalhos de campo. Às exestagiárias do Projeto Restinga, Viviane Stern da Fonseca, Daniele S. Garcia e Silvana M. Schneider, pela ajuda em diversas fases do trabalho. 


\section{REFERÊNCIAS BIBLIOGRÁFICAS}

Almeida, S.S. 1990. Clareiras naturais na amazônia central: abundância, distribuição e aspectos da colonização vegetal. Manaus. INPA-FUA. Dissertação de Mestrado. 125p.

Araujo, D.S.D. 1997. Cabo Frio Region. In Davis et. al. (eds.) Centres of Plant Diversity: a guide and strategy for their conservation. The Americas. Vol.3. Oxford. WWF/IUCN, p. 373-375. 2000. Análise florística e fitogeográfica das restingas do Estado do Rio de Janeiro. Rio de Janeiro. UFRJ/ PPGE. Tese de Doutorado. 176p. . \& Peixoto, A. L. 1977. Renovação de uma comunidade vegetal de restinga após uma queimada. Trabalhos do XXVI Congresso Nacional de Botânica. Academia Brasileira de Ciências. p. 1-17. . Oliveira, R.R., Lima, E. \& Ravelli Neto, A. 1997. Estrutura da vegetação e condições edáficas numa clareira de mata de restinga na Reserva Biologica Estadual da Praia do Sul (RJ). Revista Brasileira de Ecologia 1(2):36-43.

Assumpção, J. \& Nascimento, M.T.N. 2000. Estrutura e composição florística de quatro formações vegetais de restinga no complexo lagunar Grussaí/Iquipari, São João da Barra,RJ,Brasil. Acta Botanica Brasilica 14(3):301-315.

Barbosa, J.C.M.H. 1948. Fixação de dunas e seu aproveitamento. O problema das dunas da restinga da Marambaia. Anuário Brasileiro de Economia Florestal 1(1):312-333.

Bazzaz, F.A. \& Pickett, S.T.A. 1980. Physiological ecology of tropical succesion: a comparative review. Annual Review of Ecology and Systematics 11:287-310.

Bernacci, L.C., Goldenberg, R. \& Metzger, J.P. 1998. Estrutura florística de 15 fragmentos florestais ripários da bacia do Jacaré-Pepira (SP). Naturalia 23:23-54.
Brower, J.E. \& Zar, J. H. 1977. Field and laboratory methods of general ecology. Dubuque,IA, Wm.c. Brown Company Publishers, $194 \mathrm{p}$.

Budowski, G. 1963. Forest succesion in tropical lowlands. Turrialba 13:42-44. 1965. Distribution of tropical American rain forest species in the ligth of successional process. Turrialba 15: $40-42$.

1966. Los bosques de los tropicos húmedos de América. Turrialba 16:278285.

Carvalhaes, M.A. \& Mantowani, W. 1998. Florística de mata sobre restinga na Juréia, Iguape, SP. Anais do IV Simpósio de Ecossistemas Brasileiros. Publicação Aciesp 104(2):37-48.

Carrasco, P.G. \& Castanheira, S.A. 2000. Produção de mudas de espécies arbóreas de restinga para recuperação de áreas degradadas em Ilha Comprida, SP. Anais do V Simpósio de Ecossistemas Brasileiros: Conservação. Publicação Aciesp 109 (4):319-324.

Castellani, T.T. 1986. Sucessão secundária inicial em mata tropical semidecídua após pertubação por fogo. Campinas, UNICAMP. Dissertação de Mestrado. 180p.

. \& Stubblebine, W.H. 1993. Sucessão secundária inicial em mata tropical mesofila, após perturbação por fogo. Revista Brasileira de Botânica 16(2):181-203.

Cirne, P. \& Scarano, F.R. 1996. Rebrotamento após fogo de Andira legalis (Leguminosae) em restinga fluminense. In: Miranda, H.S. Saito,C.H. \& Dias, B.F.S. (orgs) Impactos de queimada em áreas de cerrado e restinga. Brasília, UNB. p.128-137.

Custódio Filho, A., Franco, G.A.D.C. \& Dias, A.C. 1984. Composição florística de um trecho de floresta pluvial atlântica em regeneração natural, após desmatamento diferenciado em Pariquera-Açú, SP- 
Regeneração de um trecho de floresta de restinga na Reserva Ecológica Estadual de Jacarepiá,

Saquarema, Estado do Rio de Janeiro: II - Estrato arbustivo

Brasil. Revista do Instituto Florestal 6: 87-98.

Domingues, A.J.P., Brandão, A.M.P.M., Guerra, A.J.T., Domingues, CN., Kuhlmann, E., Sant'Ana, E. M., Lima, G.R., Silva, L.M., Whately, M.H., Alonso, M.T.A., Bulhões, M.G., Régis, W.D.E. \& Silva, Z.L. 1976. Estudo do relevo, hidrografia, clima e vegetação das regiões programa do Estado do Rio de Janeiro. Boletim Geográfico 34(248):5-73.

Dorneles, L.P.P. \& Negrelle, R.R.B. 2000. Aspectos da regeneração natural de espécies arbóreas da Floresta Atlântica. Iheringia, Série Botânica 53:85-100.

Durigan, G., Franco, G.A.D.C., Pastore, J. A. \& Aguiar, O.T. 1997. Regeneração natural da vegetação de cerrado sob floresta de Eucalyptus citriodora. Revista do Instituto Florestal 9(1): 71-85.

Dunphy, B.K., Murphy, P. G. \& Lugo, A.E. 2000. The tendency for trees to be multiple-stemmed in tropical and subtropical dry forests: studies of Guanica forest, Puerto Rico. Tropical Ecology 41(2):161-167.

Finegan, B.1984. Forest succession. Nature 312:109-114.

Fonseca, V.S. 1998. Etnobotânica da Reserva Ecológica Estadual de Jacarepiá: um ensaio. Rio de Janeiro. Monografia de Bacharelado em Ciências. Universidade Santa Úrsula, 96p.

Gentry, A.H. 1978. Diversidade e regeneração da capoeira do INPA, com referência especial as Bignoniaceae. Acta Amazônica 8(1):67-70.

Gomez-Pompa, A. \& Burley, F.W. 1991. The management of natural tropical forests. In: Gomez Pompa, A; Whitmore, T. C. \& Hadley,M. (eds.). Rain Forest: Regeneration and Management. Man and Biosphere Series V.6. Paris. The Pathernon Publishing Group, p.03-17.

Gonçalves, D.B. \& Sá, C.F.C. 1998. Dinâmica da regeneração em floresta de restinga após perturbação por tratores. Anais do
IV Simpósio de Ecossistemas Brasileiros. Publicação Aciesp 104 (3):272279.

Hartshorn, G.S. 1980. Neotropical forest dynamics. Biotropica (supl.) 12:23-30.

Hueck, K. 1972. As Florestas da América do Sul: ecologia, composição e importância econômica. São Paulo. Polígono/Ed. Universidade de Brasília, 466p.

Juvêncio, I. 1959. Fixação de dunas. Boletim Geográfico 17(149):116-124.

Kauffman, J.B. 1991. Survival by sprouting following fire in tropical forests of the eastern amazon. Biotropica 23(3):219224.

Laurance, W.F., Ferreira, L.V., Rankin-deMerona, J.M. \& Laurance, S.G. 1998. Rain forest fragmentation and the dynamics of amazonian tree communities. Ecology 79(6):2032-2040.

Mathes, L. A. F. 1992. Dinâmica da sucessão secundária em Mata, após ocorrência de fogo. Santa Genebra-Campinas, São Paulo. Campinas, UNICAMP. Tese de Doutorado. 216p.

Mariano, G., Crestana, C.S.M., Batista, E.A. Giannotti, E. \& Couto, H.T.Z. 1998. Regeneração natural em área a margem de represa, no município de Piracicaba, SP. Revista do Instituto Florestal 10(1): 81-93.

Martins, S.V. \& Rodrigues, R.R. 1999. Produção de serapilheira em clareiras de uma floresta estacional semidecidual no município de Campinas, SP. Revista Brasileira de Botânica 22(3):405412.

Matos, H.P. 1947. Fixação de dunas e areias movediças. Revista Florestal 6(1):47-65.

Miranda, R.U., Barroso, D.G., Marinho, C.S. \& Carvalho, D.A.C. 1997. Estudo so-bre a vegetação em dunas de rejeito de mineração no litoral norte do Estado da Paraíba. Revista Árvore 21(3):345351.

Moares, R.M., Delliti, W.B.C., Rinaldi, M.C.S. \& Rebelo, C.F. 1998. Ciclagem mineral 
em mata atlântica de encosta e mata sobre restinga, Ilha do Cardoso,SP: nutrientes na serrapilheira acumulada. In: Anais do IV Simpósio de Ecossistemas Brasileiros. Publicação Aciesp 104(2): 71-77.

Moura, A.E.C. 1995. Estudo das primeiras etapas sucessionais em uma área de restinga degradada na Barra do Jucú,Vila Velha,ES. Vitória. UFES. Monografia em Ecologia e Recursos Naturais. 124p.

Moreno, P. 1977. Latencia e viabilidad de semillas de arboles tropicales. Interciencia 2:298-302.

Nascimento, H.E.M., Dias, A.S., Tabanez, A.A.J. \& Viana, V. M. 1999. Estrutura e dinâmica de populações arbóreas de um fragmento de floresta estacional semidecidual na região de Piracicaba, SP. Revista Brasileira de Biologia 59(2):239342.

Newel, S.J. \& Tramer, E.J. 1978. Reproductive strategies in herbaceous plant communities during sucession. Ecology 59:228-234.

Nunes, J.A.A. 1998. Caracterização estrutural, fisionômica e florística da vegetação de restinga do complexo lagunar Grussaí/Iquipari - São João da Barra, RJ. Campos, UENF. Dissertação de Mestrado. $104 \mathrm{p}$.

Oliveira, R.R. 1999. O rastro do homem na floresta: sustentabilidade e funcionalidade da Mata Atlântica sob manejo caiçara. Rio de Janeiro, UFRJ/PPG. Tese de Doutorado. 148p.

. \& Coelho Neto, A.L. 1996. O rastro do homem na floresta: a construção da paisagem da Reserva Biológica Estadual da Praia do Sul (Ilha Grande/RJ) a partir das intervenções antrópicas. Albertoa 4(10): 109-116.

Oliveira Filho, A.T. \& Carvalho, D.A. 1993. Avaliação da recomposição da cobertura vegetal de dunas de rejeito de mineração em Mataracá/PB. Acta
Botânica Brasilica 7(2):107-117.

Rizzini, C.T. 1979. Tratado de Fitogeografia do Brasil. Vol 2. São Paulo. Hucitec/EDUSP. 374 p.

Richards, P.W. 1952. The Tropical Rain Forest, an Ecological Study. Cambridge. Cambridge University Press.

Rodrigues, R.R. \& Leitão-Filho, H.F. 2000. Matas ciliares: conservação e recuperação. São Paulo. EDUSP/ FAPESP. 320p.

Sá, C.F.C. 1992. A vegetação da Restinga de Ipitangas, Reserva Ecológica Estadual de Jacarepiá: Saquarema (RJ): fisionomia e listagem de angiospermas. Arquivos do Jardim Botânico do Rio de Janeiro 31:87-102.

1993. Regeneração de um trecho de floresta de restinga na Reserva Ecológica Estadual de Jacarepiá,Saquarema/RJ. Rio de Janeiro, UFRJ. Dissertação de Mestrado. $167 \mathrm{p}$.

. 1996. Regeneração em uma área de floresta de restinga na Reserva Ecológica Estadual de Jacarepiá, Saquarema/RJ: I- Estrato herbáceo. Arquivos do Jardim Botânico do Rio de Janeiro 34(1):177-192.

Sampaio, E.V.S.B., Araújo, E.L., Salcedo, I. H. \& Tiessen, H. 1998. Regeneração da vegetação de caatinga após corte e queima em Serra Talhada, PE. Pesquisa Agropecuária Brasileira 33(5): 621-632.

Silva, M.B.R. \& Zamith, L.R. 1994. Recomposição florística de restingas do Município do Rio de Janeiro. In: Anais do I Encontro Brasileiro de Ciências Ambientais. Vol 1:363-371.

Silva $F^{\circ}$, M.C. Scarano, F.R. \& Cardel, F.S. 1995. Regeneration of an Atlantic forest formation in the understorey of a Eucalyptus grandis stand in southeastern Brazil. Journal of Tropical Ecology 11:148-152. 
Regeneração de um trecho de floresta de restinga na Reserva Ecológica Estadual de Jacarepiá,

Silva Jr, M.C. 2001. Comparação entre matas de galeria no Distrito Federal e a efetividade do código florestal na proteção de sua diversidade arbórea. Acta Botânica Brasilica 15(1): 139-146)

Soffiati, A. 1996. O nativo e o exótico: perspectivas para a história ambiental na ecorregião norte-noroeste fluminense entre os séculos XVII e XX. Rio de Janeiro. UFRJ. Dissertação de Mestrado. $287 \mathrm{p}$.

Tabanez, A.A., Viana, V.M. \& Dias, A.S. 1997. Consequiência da fragmentação e do efeito de borda sobre a estrutura, diversidade e sustentabilidade de um fragmento de floresta de planalto de Piraci-caba, SP. Revista Brasileira de Biolo-gia 57(1):47-60.

Tabarelli, M. \& Mantowani, W. 1997. Colonização de clareiras naturais na floresta atlântica no sudeste do Brasil. Revista Brasileira de Botânica 20:57-66. 1999a. A regeneração de uma floresta tropical montana após corte e queima (São Paulo-Brasil). Revista Brasileira de Biologia 59(2):239-250.

1999b. Clareiras naturais e a riqueza de espécies pioneiras em uma floresta atlântica montana. Revista Brasileira de Biologia 59(2):251-261.

Uhl, C., Buschbacher, R. \& Serrão, E.A.S. 1988. Abandoned pastures in eastern Amazonia. I. Patterns of plant succession. Journal of Ecology 76:663-681.

Vasquez-Yanes, C. 1976. Estudios sobre la ecofisiologia de la germincion en una zona cálido-húmeda de México. In: GomezPompa, A.; Vásquez-Yanes, C.; Rodríguez, S. Del A. \& Cervera, A. B. (eds.) Investigaciones sobre la regeneración de selvas en Veracruz, México. México, Compañia Editorial Continental. p.579-593.

Viana, V. M., Tabanez, A.J.A. \& Martinez, J.L.A. 1992. Restauração e manejo de florestas tropicais. In: Anais do $2^{\circ}$. Con- gresso Nacional sobre Essências Nativas. Vol. 3:401-406.

Whitmore, T.C. 1990. An introduction to tropical rain forests. Oxford. Clarendon Press, 226p.

Zaluar, H.T. \& Scarano, F.R. 2000. Facilitação em restingas de moitas: um século de busca por espécies focais. In: Esteves, F. A. \& Lacerda, L. D. Ecologia de Restingas $e$ Lagoas Costeiras. Rio de Janeiro. NUPEM-UFRJ. p 3-23.

Zamith, L.R. \& Dalmaso, V. 2000. Revegetação de restingas degradadas no município do Rio de Janeiro/RJ. In: Anais do V Simpósio de Ecossistemas Brasileiros: Conservação. Publicação Aciesp 109 (4):227-234. 